\title{
PROPOSAL FOR A HOLISTIC MINDFULNESS-BASED INTERVENTION PROGRAM FOR THE CLASSROOM TEACHERS WITH MENTAL HEALTH PROBLEMS
}

\author{
Nguyen Phuong Lan ${ }^{1}$ \\ Faculty of Tourism, \\ Ho Chi Minh City University of Food Industry (HUFI), Vietnam. \\ (Email: lannp@hufi.edu.vn) \\ Huynh Cong Du' \\ Department of Psychology, \\ University of Labor and Social Affairs (ULSA2), Ho Chi Minh City, Vietnam. \\ (Email: duhc@ldxh.edu.vn)
}

Received date: $19-07-2019$

Revised date: 23-07-2019

Accepted date: 29-07-2019

Published date: 15-09-2019

To cite this document: Nguyen, P. L., \& Huynh, C. D. (2019). Proposal for a Holistic Mindfulness-Based Intervention Program for the Classroom Teachers with Mental Health Problems. International Journal of Education, Psychology and Counseling, 4 (32), 259-272.

DOI: $10.35631 /$ IJEPC.4320024

Abstract: In the school setting, the mental health problems of students have been often discussed. Teachers have also been found to have the mental health problems, which could have a detrimental effect upon all of those students who are associated with him or her, but there has been no or very few interventions designed to help them. To address this, the current study has two main goals: 1) to review related literature in order to categorize common mental health problems among teachers and 2) to propose a holistic mindfulness-based intervention program for the teachers. The proposed program consists of 2 modules with 9 sessions. Each session is expected to last in 60 minutes.

Keywords: Classroom Teachers' Mental Problems, Anxiety, Depression, Emotional, Mindfulness-Based Intervention

\section{Introduction}

An optimal classroom climate has been described to have low levels of conflict and disruptive behaviour, smooth transitions from one type of activity to another, appropriate expressions of emotion, respectful communication and problem solving, strong interest and focus on tasks, and supportiveness and responsiveness to individual differences and students' needs (La Paro \& Pianta, 2003). In fact, in school setting, mental health of students has been largely discussed and concerned and past studies have focused on the effectiveness of classroom-learning environment (CLE), in which teachers' instructional techniques, teacher-student interactions (Connor et al., 2010; Hamre \& Pianta, 2005), and teachers' role in school students' mental 
health has been emphasized ( Nikolaou et al, 2017). However, fewer studies have investigated the contributions of teachers' psychological health, even in light of growing concern about the effects of teachers' chronic stress on educational quality (Alliance for Excellent Education, 2005). Individual depressive symptoms, such as stress and poor emotional regulation, have been found to affect teachers' contribution to the CLE. Mashburn et al. (2006) found that teachers who exhibited more maladaptive psychological characteristics were more likely to rate their relationships with students as hostile.

Because teachers have also been found to have mental health problems, which could have a detrimental effect upon all of those students who are associated with him or her, but there has been very few interventions designed to help them. To address this, the current study has two main goals: 1) to review related literature in order to categorize common mental health problems among teachers and 2) to propose a holistic mindfulness-based intervention program for the teachers.

\section{Review of Related Literature}

\section{Definition of Terms}

According to Medilexicon's medical dictionary, mental health is " Emotional, behavioral, and social maturity or normality; the absence of a mental or behavioral disorder; a state of psychological well-being in which one has achieved a satisfactory integration of one's instinctual drives acceptable to both oneself and one's social milieu; an appropriate balance of love, work, and leisure pursuits." And according to the WHO (World Health Organization), mental health is: .... a state of well-being in which the individual realizes his or her own abilities, can cope with the normal stresses of life, can work productively and fruitfully, and is able to make a contribution to his or her community."

Psychological traits of mental health include factors of anxiety, depression, and loss of behavioural /Emotional control (The Mental Health Act, 1987). The current paper would like to employ these factors as guidelines to review the teachers' mental health problems.

\section{Teachers' Mental Health Problems}

Past studies conducted on teaching professional, has shown that teachers also have mental health problems and these problems have detrimental effect upon theirs students as below.

The first factor of teachers' mental health problem is anxiety. For examples, recently, a 2017 educator work-life study survey conducted by the American Federation of Teachers and the Badass Teachers Association confirmed teacher anxiety is higher than most other professions. According to the survey, 61 percent of educators reported their work was "always" or "often" stressful-twice the rate of other professions (American Federation of Teachers, 2017). In their study on inherent personal traits behind teacher anxiety such as personality, Fontana and Abouserie (1993) found that the more extroverted teachers were, the less stress they were likely to experience. In addition to internal factors, teachers' anxiety has been attributed to the influence of external agents. Gresham (2008) found that there was a significant correlation between high levels of efficacy and low levels of anxiety. Ferguson et al. (2012) found that sources of anxiety or stress identified in the literature including time constraints and heavy workloads.

The second common factor is depression: Teachers are responsible for the implementation of many important classroom factors, they play a crucial role in defining the learning context in 
which students participate (Eccles \& Roeser, 1999). Therefore, teacher practices and the classroom-learning environment (Q-CLE) are important contributors to children's development (Hamre \& Pianta, 2007). In connection with the mentioned viewpoints, Hamre et al. (2008) found that classroom emotional climate and teacher stress level were predictive of teachers' reports of conflict, over and above students' diagnosed behaviour problems. While these studies strongly support the notion that teachers' everyday interactions with students, classroom management, reactions to student behaviour, and ability to implement curriculum are impacted by the presence of depressive symptoms, few conceptualize "depression" as a whole construct composed of multiple symptoms, while those that do have found mixed results. Additionally, Li Grining et al., (2010); and Swartz \& McElwain (2012) discovered that teachers' negative psychological characteristics may influence classroom. For example, personal stress in teachers has been associated with lower quality classroom interactions, and teachers who have stronger emotion regulation are more likely to reinforce positive student behaviour and respond supportively to students' negative emotions; and in their study, McLean and Connor (2015) also revealed that depression in teachers has been found to have impacts classroom learning and that teachers who have more symptoms of depression may have a negative influence on classroom quality and student achievement.

The third factor in teachers' mental health problem is emotional: Teaching is a high-stress profession, and many teachers experience serious emotional problems related to the stress of their job (Eaton et al, 1990). Similarly, teaching is an emotional activity (Hargreaves, 1998, 2001), and as such, it carries with it our own emotional experience as well as that of those who surround us. Therefore, according to Miller DF, Wiltse J. (1979) classroom environment is affected by the emotional stability of the teacher. A teacher with personal mental health problems can have a detrimental effect upon all of those students who are associated with him or her. Frenzel, Götz, Stephens, and Jacob (2009) describe the relationship that occurs between teacher emotions and student behavioural responses. Their model proposes that teachers' emotions, impacted by student behaviours, in turn influence instruction; thus continuing the cyclical effect in the impact of teachers' emotions on student behaviours and outcomes. For those reasons, there have been studies conducted to investigate the impact teachers' emotion upon teaching and learning, for examples, Pekrun, Goetz, Titz and Perry (2002) found that while negative deactivating emotions on the part of the teacher take a negative toll in the classroom, positive activating emotions render a positive effect on student learning. Similarly, teachers are susceptible to the influence that emotions exert over them (Day \& Leitch, 2001). Students can learn that a topic or learning task is valuable by teachers' comments, as well as by observing their teacher's enjoyment of the topic or learning task. High task values acquired though such "value induction" (Pekrun, 2000,) may in turn have positive effects on students' own enjoyment of learning. Frenzel et al. (2009) found that enjoyment of teachers was positively related to that of students, even when controlling for student enjoyment in the previous school year, and that enjoyment as reported by teachers was positively associated with student perceptions of teacher enthusiasm, and teacher enthusiasm in turn was positively linked to students' levels of enjoyment. This implied that that teachers do make a difference in terms of students' emotional experiences in the classroom and in terms of how students' experiences change across years.

So far, there has been very few existing interventions designed to address teachers' mental problems found in literature while there has recently been a research trend and a good amount of interest in mental health benefits of mindfulness (Brown and Ryan, 2003). 


\section{Mindfulness and Its Benefits}

Recently, there has been an amount of interest in mental health benefits of mindfulness (Brown and Ryan, 2003). Mindfulness which involves bringing a certain quality of attention to moment by moment experience (Kabat-Zinn, 1990), is the heart of Buddhist mediation practice and psychology (Siegel and Fulton, 2005). According to Siegel (2009), mindfulness is actually not only a form of attention training (which many investigators studied it as) and it is not only a form of affect regulation training (which some people were studying it as being as well). Maybe mindfulness is actually a relational process where you become your own best friend. Mindfulness appears to change how we see ourselves in the world; our experience of the selfchanges with mindfulness. Mindfulness is an integrative process that promotes well-being in body, mind and relationships. Baer et al. (2006) described mindful awareness as: (1) act with awareness; (2) be less reactive; (3) be non-judgemental; (4) develop the ability to label and describe with words the internal world and (5) self-observe. Mindful awareness contains attention focusing and includes behaviours such as intense looking at objects or scenes, careful examining, fingering and inspecting them with interest for details (Ruff \& Rothbart 1996).

Psychotherapy patients are increasingly seeking the psychotherapists who understand their meditation practice; therefore, most therapists are familiar with meditation as a relaxation technique (Benson, cited in Agnes, 2009). Mindfulness practice brings about many psychological and mental health benefits. For instance, mindfulness enables its practitioners: to develop ability to observe self and thus becomes less identified with the contents of consciousness (Segal, Williams \& Teasdale, 2002); to see thoughts as merely thinking without feeding or fighting them (Sogyal, 1992); to stay present to the other person without being caught up in destructive emotions (Doherty, 1997). Moreover, mindfulness allows covert desensitization to unpleasant thoughts and negative feelings that make one suffer from himself (Breslin 2002).

Mindfulness is also beneficial to the mind and body. For example, a 2006 qualitative study followed the effects of one year of Transcendental Meditation on ten middle school students showed that students gained greater ability of self-control and improved social relationships, as well as better academic performance (Rosaen, 2006). Other investigators have found that Sahaja Yoga Meditation, an awareness practice related to mindfulness could reduce child'ADHD symptom; enhanced the self-esteem of the children and improved relationship between parents and the child (Harrison et al., 2004). In another study for adolescents with ADHD, mindfulness training significantly reduced symptoms associated with their disorder (Zylowksa et al., 2008). Iyengar Yoga as a complement to medication in the treatment of depression was found to significantly reduce in overall depression, anger, and anxiety among participants. Participants also consistently rated their moods higher after the completion of each class than before each one commenced (Shapiro et al., 2007). In one 6-week study with anxious children, teachers reported an improvement in academic functioning and decrease in symptoms of anxiety in the children (Semple et al., 2005). A mindfulness intervention for several adolescents with conduct disorder, resulted in a significant decrease in aggressive behaviour. They reported benefits from mindfully returning their attention to the soles of their feet during distressing situations (Singh et al., 2007). Mindfulness-based cognitive therapy significantly reduced observable internalizing and externalizing symptoms (Lee et al., 2008).

Mindfulness intervention is also helpful in educational settings. In their study of MBSR for primary school teachers included 10 intervention participants and no control group, Gold et al. (2010) discovered that teachers reported improvement in depression and stress and greater 
accepting without judgment (a component of the mindfulness scale). Another study focused on meditation coupled with emotion regulation training for female teachers conducted by Kemeny et al. (2012) revealed that teachers in the experimental group as compared to the control group reported more positive trait affect and increased mindfulness, showed improved ability to recognize others' emotions, as well as greater sensitivity to compassion-related words in a behavioural task, and amount of practice was related to less physiological reactivity. Recently, in a randomized controlled pilot trial of a modified Mindfulness-Based Stress Reduction course (mMBSR) adapted specifically for teachers, Lisa et al. (2013) found that participants showed significant reduction in psychological symptoms and burnout, improvements in observer-rated classroom organization and performance on a computer task of affective attentional bias, and increases in self-compassion. Furthermore, changes in mindfulness were correlated in the expected direction with changes across several outcomes (psychological symptoms, burnout, and sustained attention) in the intervention group. This Results suggest the mindfulness may be a promising intervention to support teachers.

\section{Synthesis of The Literature Review}

While the articles reviewed in this research described that teachers has some symptoms of mental health problems including anxiety, depression and emotional, there has been very little efforts to address mental health problems among teachers to help them stay focus on teaching and be free from the problems. There has recently been a research trend and a good amount of interest in mental health benefits of mindfulness for teachers but showed a promising intervention.

The current study and the previous ones have some points in common. For instance, they all address the same concern of the mental health problems among teachers. However, the contribution of the current study is to categorize the concrete factors of mental health problems experienced by teachers in a more systematic way for a better understanding and assessment and at the same time to propose a holistic mindfulness-based intervention program, adding one more treatment approach to the field of educational psychology in general and teaching professionals in particular.

\section{Conceptual Framework}

This paper utilizes multiple concepts, research findings, and intervention model derived from related literature as conceptual framework for proposing an intervention model in this study. Concretely, the work incorporates three symptoms of mental health experienced by teachers including anxiety, depression and emotional as problems to be addressed in the current proposed intervention model. And the intervention model prosed in this study will be based on mindfulness approach which was found to be a research trend and a promising intervention to address these problems of teachers (Lisa et al., 2013). This proposed mindfulness-based intervention model including six factors: physical mindfulness, mental mindfulness, emotional mindfulness, relational mindfulness; and spiritual mindfulness which are called holistic (Krishnamurti, 2003). Figure 1 below will illustrate the conceptual framework including factors to be included which serves as basis for the intervention proposal. 




Figure 1: Conceptual Research Framework

- The mental health problems of teacher in this study refer to anxiety, depression and emotional problems.

-The holistic mindfulness-based intervention in this study refers to mindful experience about wholeness of body, mind, and spirit of students in class, which is called holistic approach (Krishnamurti, 2003) consisting of five components: physical, mental, emotional, relational and spiritual mindfulness. Each component contains one major technique to help the teachers with moment by moment experience.

- Physical Mindfulness (body scan technique), a process of moving attention from head to toes, observing sensations in the different regions of the body to enable participants to become aware of themselves physically;

- Mental Mindfulness (mantra technique), a meditation on a word/ phrase that gives one a meaning/ power of concentration when mental suffering arises such as self-negative judgment or unhappy thoughts about the self;

- Emotional Mindfulness (emotion anchor technique), a way of freeing from one's own emotional sufferings using deep breathing to enhance awareness of what is happening in the body;

- Relational Mindfulness (metta techniquel loving-kindness meditation), a good intention or compassion one wants to extend to the self, teachers and classmates;

- Spiritual Mindfulness (centering meditative prayer), a way of adding depth of meaning and building of faith through the grace of contemplation on a meaningful word that best supports one's sincere intention.

Proposal for a Holistic Mindfulness-based Intervention Program:

The intervention consists of 2 modules with 9 sessions. Each session is expected to last in 60 minutes. Please see Table 1 for a detailed description of the modules. 
Table 1

\begin{tabular}{|c|c|c|}
\hline$\underset{1}{\text { Module }}$ & Sessions & Preliminary \\
\hline \multirow[t]{2}{*}{$\begin{array}{c}\text { Day } \\
1\end{array}$} & Assessment & $\begin{array}{l}\text { Session objectives: To get the baseline for the selection of the } \\
\text { participants. } \\
\text { Expected outcomes: } \\
\text { Strategy: Teachers are invited to complete the scale: Mental } \\
\text { Health Inventory (MHI) } 38\end{array}$ \\
\hline & $\begin{array}{l}\text { Preparation of } \\
\text { the } \\
\text { participants }\end{array}$ & $\begin{array}{l}\text { - Getting to know each other } \\
\text { - Orientation on confidentiality } \\
\text { - Establishing the rules during the sessions } \\
\text { - Expectations } \\
\text { - Getting nick names or emails for later feedbacks }\end{array}$ \\
\hline
\end{tabular}

Day Educating the Session objectives: To help teachers discover consequences of 2 participants mental health problems

Expected outcomes: The participants will be able to understand the consequences

Strategy:

- Lectures on the mental health problems and their consequences.

- The participants are invited to reflect the questions: What mental health problems do you often experience: anxiety, depression or emotional problem?

- Group sharing: The participants will be invited to share their reflections in group (s).

\begin{tabular}{|c|c|c|}
\hline Module 2 & Session No. & Intervention Sessions \\
\hline $\begin{array}{c}\text { Day } \\
\mathbf{3}\end{array}$ & $\begin{array}{l}\text { Educating of } \\
\text { Mindfulness }\end{array}$ & $\begin{array}{l}\text { Session objectives: To introduce the benefits of mindfulness and } \\
\text { to demonstrate general mindfulness techniques } \\
\text { Expected outcomes: } \\
\text { - The participants will become aware of the importance of } \\
\text { mindfulness practice, and be familiar with themselves with the } \\
\text { basic techniques and skills to apply in daily life. } \\
\text { - The participants will be able to stay in the present, to feel peace } \\
\text { and happiness in their life. } \\
\text { Strategy: } \\
\text { - Lecture } \\
\text { - The participants watch a video clip of a mantra song: "Que Cera } \\
\text { Cera" by Doris Day, and will be invited to sing altogether. } \\
\text { - Practice 1: Basic Mindfulness Exercises: sitting down, relaxing } \\
\text { and breathing deeply following the facilitator's instruction. } \\
\text { - Practice 2: Waiting For Yourself Exercise following the } \\
\text { facilitator's instruction. } \\
\text { - Home work: Practice seeing, hearing exercise and sitting } \\
\text { meditation guided by the hand-outs. }\end{array}$ \\
\hline $\begin{array}{c}\text { Day } \\
4\end{array}$ & $\begin{array}{c}\text { Physical } \\
\text { mindfulness }\end{array}$ & $\begin{array}{l}\text { Session objectives: } \\
\text { - To introduce the body scan practice and help the participants } \\
\text { stay focused on the different parts of the body and anchor their } \\
\text { awareness in the present moment; }\end{array}$ \\
\hline
\end{tabular}


- To help the participants practice the body scan exercise daily at their convenient time;

- To help the participants stop "running from themselves" for becoming physically mindful about what is happening to their bodies.

\section{Expected outcomes:}

- The participants will become aware of themselves physically and give kindness to themselves physically as a way to reduce anxiety and depression.

- The participants will be able to learn the experience of settling their body

- The participants will be able to become aware of body sensation and practice at their convenient time.

Strategy:

- Review of the previous session

- Lecture

Practice 1: Mindfulness of the body sensations: The participants will be asked to notice one tense part of the body and soften it using relaxing breaths following the facilitator's instruction.

Practice 2: Warm hands, warm heart exercise using hot coffee or hot tea or hot water activity.

Home work: do anything you can to comfort the body when you feel discomfort. For example:

Watch funny movies;

Eating nourishing food and eat slowly and taste deeply to feel its deliciousness; ;

Drink warm water and take warm bath to warm the body;

Can you think of a few strategies to take care of yourself physically? Write down and try it.

\begin{tabular}{|c|c|c|}
\hline $\begin{array}{c}\text { Day } \\
5\end{array}$ & $\begin{array}{c}\text { Mental } \\
\text { mindfulness }\end{array}$ & $\begin{array}{l}\text { Session objectives: } \\
\text {-To introduce Mantra technique known as tool for the mind } \\
\text { when mental suffering arises such as self-negative judgment/ } \\
\text { unhappy thoughts about the self } \\
\text { - To introduce, relaxing breath technique, the most common } \\
\text { anchor for the mind } \\
\text { Expected outcomes: } \\
\text { - The participant will become aware of mental states and be able } \\
\text { to acquire common mantra techniques such as repeating one nice } \\
\text { word/phrase that is applicable to them in their current situation. } \\
\text { - The participants will be able to give anchor to their mind when } \\
\text { they notice unhealthy thoughts take place. } \\
\text { Strategy: } \\
\text { - Review of the previous lesson and share result of home works. } \\
\text { - Lecture } \\
\text { - The participant will watch a video clip about a mantra song } \\
\text { "Que Cera Cera, What Will be Will be" by Thai disable children } \\
\text { and then will be asked to repeat the phase from the song. } \\
\text { - Practice 1: Centering meditation to discover personalized } \\
\text { compassionate mantra word/ phrase. The participant will do this } \\
\text { exercise following the facilitator's instruction. }\end{array}$ \\
\hline
\end{tabular}




\begin{tabular}{|c|c|c|}
\hline & & $\begin{array}{l}\text { - Practice 2: Anchor the mind using mindfulness technique of } \\
\text { breathing. The participants will do this exercise following the } \\
\text { instruction from a video clip. } \\
\text { - Home work: What is your personal mantra in this mental state: } \\
\text { you were given a question by your teacher, but you were not able } \\
\text { find the answer? } \\
\text { Hint: you assign your students homework but they did not } \\
\text { accomplish. Your mantra phase may be: they did not finish their } \\
\text { homework, he may need help. } \\
\text { Or: your brain overworked last night to complete check your } \\
\text { students' papers. Your mantra phase maybe: poor brain! So much } \\
\text { hard but meaningful work! }\end{array}$ \\
\hline $\begin{array}{c}\text { Day } \\
6\end{array}$ & $\begin{array}{l}\text { Emotional } \\
\text { Mindfulness }\end{array}$ & $\begin{array}{l}\text { Session objectives: To introduce basic techniques and related } \\
\text { activities enabling one to be free from emotional sufferings. } \\
\text { Expected outcomes: The participants will become aware of and } \\
\text { accept negative feelings and become friendlier toward un- } \\
\text { comfortable emotions and toward oneself } \\
\text { Strategy: } \\
\text { - Review of the previous session and sharing the experience } \\
\text { from homework exercise. } \\
\text { - Presentation of Emotional Free Technique (EFT) } \\
\text { Practice 1: Mindfulness of difficult emotion using relaxing } \\
\text { breaths following the facilitator's instruction. } \\
\text { Practice 2: Soft soft soft! Allow allow allow! and love love } \\
\text { love activity using relaxing breaths to move one from physical to } \\
\text { mental and to comfortably emotional level. The participants do } \\
\text { this activity following the facilitator's instruction. } \\
\text { Homework: } \\
\text { Try this: treat yourself with one of the following activities: } \\
\text { listening to music, going to church, riding a bike, working in the } \\
\text { garden, cooking delicious food, collecting shells. } \\
\text { Do you have any way to be kind to yourself emotionally? Keep } \\
\text { in mind that engaging in activities that are intrinsically enjoyable, } \\
\text { rather than those that feel like work, is a way to be kind to } \\
\text { yourself emotionally. }\end{array}$ \\
\hline Day 7 & $\begin{array}{c}\text { Relational } \\
\text { Mindfulness }\end{array}$ & $\begin{array}{l}\text { Session objectives: To introduce loving-kindness meditation } \\
\text { (Metta Meditation) to help one stop isolating but relate oneself to } \\
\text { human beings, for example: connect to students and co-teachers: } \\
\text { Expected outcomes: } \\
\text { - The participants will be aware that they are part of class. } \\
\text { - The participants should be able to kindly relate to others as } \\
\text { students and co-teachers because how to relate to others have } \\
\text { huge impact on how they feel inside themselves too. } \\
\text { Strategy: } \\
\text { - Review of the previous session and sharing the experience } \\
\text { from the practice at home } \\
\text { - Lecture } \\
\text { - Demonstrate of Loving Kindness meditation modality by a } \\
\text { Video clip. }\end{array}$ \\
\hline
\end{tabular}


Practice 1: Loving Kindness meditation/ whishing happiness for others

The participants are invited to imagine how hard the learning task of their students is or how difficult of a lesson is for students to understand and do exercises, then give them good wish. The participants will follow the facilitator's instruction. At the end of the activity, the participants will be asked to continue reciting the following Metta phrases:

1. May my students be healthy and learn well.

2. May my students be happy and safe all the time.

2. May my co-teachers be fine all the time and teach well.

3. May my students accept limitations of teachers

Practice 2: Loving Kindness meditation/ Wishing happiness for oneself

The participants will be asked to give themselves loving attention following the facilitator's citations. At the end of the activity, the participants will be asked to continue reciting the following Metta phrases:

1. May I be fine all the time;

2. May I teach well;

3. May I be able to concentrate in class all the time;

4. May I accept my limitation as a teacher;

Home work: Take your time and create some Metta phrase in your own words that shape your experience. Here are some examples:

May I be kind to myself and my students in classroom

May I truly be happy

May I find peace in this uncertain world

May I have happiness and causes of happiness

May I live in peace without too much attachment and too much aversion

May I be free from anxiety

May I love and be loved.

May we be completely free from all dangers

May we happy completely teaching-learning

. May we have peace in mind and heart

$\begin{array}{cc}\text { Day } & \text { Spiritual } \\ \mathbf{8} & \text { Mindfulness }\end{array}$

Session objectives: To Introduce advantages of spiritual benefits and steps to Centering Prayer to the participants.

\section{Expected outcomes:}

- The participants will become aware of the importance of spirituality in human life.

- The participants will nourish their spirit as a way to cultivate closeness to an idea- transcendent being, a process that one hopes and accepts selfish desires and personal limitations.

Strategy:

- Review of the previous session and sharing of the personal nice phrase.

- Lecture on centering meditative prayer, a spiritual approach. 


\begin{tabular}{|c|c|c|}
\hline & & $\begin{array}{l}\text { Practice: Christian, Buddhist, Ancestral worship Prayer/ } \\
\text { Meditation using relaxing breaths following demonstration from } \\
\text { a video clips. } \\
\text { Home work: } \\
\text { Before going to bed, kindly open prayer book of your religion } \\
\text { or any book meaning to you and a passage. Choose a word that } \\
\text { you like from the text and payer over it using the technique learnt } \\
\text { and practiced. Kindly write down your experience and share with } \\
\text { each other in the next meeting. } \\
\text { Do you have any other way to enhance spiritual life? }\end{array}$ \\
\hline $\begin{array}{c}\text { Day } \\
9\end{array}$ & $\begin{array}{l}\text { Evaluation } \\
\text { and } \\
\text { recognition }\end{array}$ & $\begin{array}{l}\text { Session objectives: To allow the participants to give feedback } \\
\text { about the program. } \\
\text { Expected outcomes: The participants will become aware of } \\
\text { strengths and limitations of the program } \\
\text { Strategy: } \\
\text { Sharing experiences about the whole program } \\
\text { Evaluation forms } \\
\text { Awarding of Certificates for the participants/ Tokens } \\
\text { Final administration of the Mental Health Inventory (38) to the } \\
\text { teachers in order to see improvement in mental health. }\end{array}$ \\
\hline
\end{tabular}

\section{Conclusions and Recommendations}

From the literature, the teachers have been found to have mental health problems in terms of anxiety, depression and emotional, which has affected teaching-learning process. The problems have not been largely dealt by different interventions. To address these issues, this paper tried to systematically rearrange the problematic behaviours in categories for a better understanding and assessment. Moreover, in the trends of research and application of mindfulness benefits, this study proposed a holistic mindfulness-based intervention to address to the problem concerned because in the country no such an intervention model, so far, has been built. The proposed intervention program in this study aims to add one more tool to the field of mental health and educational psychology, concretely to the educators, teachers, guidance counsellors and school psychologists. This program consists of 2 modules as mentioned. Since this is just a proposed intervention model, the educators, teachers, guidance counsellors, school psychologists and those working in mental health are highly recommended to implement this intervention program to examine whether it is effective in treating the teachers' mental health problems in classroom. Future researchers are encouraged to apply the program to validate its effectiveness for future use.

\section{References}

Alliance for Excellent Education (2005). Teacher attrition: A Costly Loss to the Nation and to the States. Washington, DC. Retrieved from https://all4ed.org/wp content/uploads/2007/06/TeacherAttrition.pdf

Agnes, G. T. (2009). Effectiveness of Mindfulness-Based Cognitive Intervention in Promoting Quality of Life of Caregivers of Cancer Patients: Unpublished Dissertation, University of Santo Tomas, Manila, Philippines.

Anne C. Frenzel, Thomas Goetz, Oliver Lu“dtke, Reinhard Pekrun, Rosemary E. Sutton (2009). Emotional Transmission in the Classroom: Exploring the Relationship between Teacher and Student Enjoyment. Journal of Educational Psychology, 101 (3), 705- 716.

American Federation of Teachers. 2017 Educator Quality of Work Life Survey. Retried from https://www.aft.org/sites/default/files/2017_eqwl_survey_web.pdf 
Baer, R.A., Smith, G.T., Hopkins, J., Krietemeyer, J. \& Toney, L., (2006). Using Self-Report Assessment Methods to Explore Facets of Mindfulness. Assessment 13(1), 27-45.

Breslin, F. C., Zack, M., \& Mcmain, S. (2002). An Information-processing Analysis of Mindfulness: Implications for Relapse Prevention in the Treatment of Substance Abuse. Clinical Psychology: Science and Practice, 9(3), 275-299.

Brown, K.W., Ryan, R.M., (2003). The Benefits of Being Present: Mindfulness and Its Role in Psychological Well-Being. Journal of Personality and Social Psychology, 84 (4), $822-$ 848.

Connor, C. M., Ponitz, C. E. C., Phillips, B., Travis, Q. M., Day, S. G., \& Morrison, F. J. (2010). First Graders' Literacy and Self-Regulation Gains: The Effect of Individualizing Instruction. Journal of School Psychology, 48, 433-455.

Day, C., \& Leitch, R. (2001). Teachers' and Teacher Educators' Lives: The Role of Emotion. Teaching and Teacher Education, 17(4), 403-415.

Doherty, R.W. (1997). The Emotional Contagion Scale: A Measure of Individual Differences. Journal of Nonverbal Behaviour, 21, 131-154.

Eaton, W. W., Anthony, J. C., Mandel, W., \& Garrison, R. (1990). Occupations and the Prevalence of Major Depressive Disorder. Journal of Occupational and Environmental Medicine, 32, 1079-1087.

Eccles, J. S., \& Roeser, R. (1999). School and Community Influences on Human Development. In M. H. Bornstein \& M. E. Lamb (Eds.), Developmental Psychology: An advanced textbook (4th ed., pp. 503-554).

Ferguson, K., Frost, L., \& Hall, D. (2012). Predicting Teacher Anxiety, Depression, and Job Satisfaction. Journal of Teaching and Learning, 8(1), 27-42.

Folkman, S., \& Lazarus, R. S. (1988). Manual for the Ways of Coping Questionnaire. Palo Alto: Consulting Psychologist Press.

Fontana, D., \& Abouserie, R. (1993). Stress Levels, Gender and Personality Factors in Teachers. British Journal of Educational Psychology, 63, 261-270.

Frenzel, A. C., Götz, T., Stephens, E. J., \& Jacob, B. (2009). Antecedents and Effects of Teachers' Emotional Experiences: An Integrative Perspective and Empirical Test. In P. A. Schutz and M. Zembylas (Eds.) Advances in Teacher Emotions Research: The Impact on Teachers Lives (pp. 129-148). New York: Springer.

Gold E, Smith A, Hopper I, Herne D, Tasey g., Hulland C (2010). Mindfulness-Based Stress Reduction (MBSR) for primary school teachers. Journal of Child and Family Studies, 19, 184-189.

Gresham, G. (2008). Mathematics Anxiety and Mathematics Teacher Efficacy in Elementary Pre-Service Teachers. Teaching Education, 19(3), 171-184.

Hargreaves, A. (1998). The emotional practice of teaching. Teaching and Teacher Education, $14,835-854$.

Hargreaves, A. (2001). Emotional geographies of teaching. Teachers College Record, 103, $1056-1080$

Hagenauer, G., Hascher, T., \& Volet, S.E. (2015). Teacher emotions in the classroom: associations with students' engagement, classroom discipline and the interpersonal teacher-student relationship. European Journal of Psychology of Education, 30(4), 385-403.

Hamre, B. K., \& Pianta, R. C. (2005). Can Instructional And Emotional Support in the FirstGrade Classroom Make a Difference for Children at Risk of School Failure? Child Development, 76, 949-967.

Hamre, B. K., \& Pianta, R. C. (2007). Learning Opportunities in Pre-School and Early Elementary Class-Rooms. In Pianta, R. C., Cox, M. J., \& Snow, K. L. (Eds.), School 
Readiness and The Transition to Kindergarten in the Era of Accountability (pp. 49-84). Baltimore, MD: Brookes.

Hamre, B. K., Pianta, R. C., Downer, J. T., \& Mashburn, A. J. (2008). Teachers' Perceptions of Conflict with Young Students: Looking Beyond Problem Behaviours. Social Development, 17, 115-136.

Kabat-Zinn, J. (1990). Full Catastrophe Living: Using the Wisdom of Your Mind to Face Stress, Pain and illness. New York: Dell Publishing.

Kemeny ME, Foltz C, Cavanagh JF, Cullen M, Giese-Davis J. (2012). Contemplative/Emotion Training Reduces Negative Emotional Behaviour and Promotes Prosocial Responses. Emotion, 12(2), 338-350

La Paro, K. M., \& Pianta, R. C. (2003). Classroom Assessment Scoring System. Charlottesville: University of Virginia Press.

Lee, J., et al. (2008). Mindfulness-Based Cognitive Therapy for Children: Results of a Pilot Study. Journal of Cognitive Psychotherapy, 22(1), 15-28

Leigh McLean and Carol McDonald Connor (2015). Depressive Symptoms in Third-Grade Teachers: Relations to Classroom Quality and Student Achievement. Child Development; 86 (3), 945-954.

Li-Grining, C., Raver, C. C., Champion, K., Sardin, L., Metzger, M. W., \& Jones, S. M. (2010). Understanding and Improving Classroom Emotional Climate in the "Real World: The Role of Teachers' Psychosocial Stressors. Early Education and Development, 21, 6594.

Mashburn, A. J., Hamre, B. K., Downer, J. T., \& Pianta, R. C. (2006). Teacher and Classroom Characteristics Associated with Teachers' Ratings of Prekindergarten's Relationships and Behaviours. Journal of Psychoeducational Assessment, 24, 367-380.

Medilexicon's medical dictionary. Definition of Mental health. Retrieved from: https://www.medicalnewstoday.com/articles/154543.php

Miller DF, Wiltse J. (1979). Mental health and the teacher. Journal of School Health, 49(7):374-7.

Nikolaou, Eleni \& Markogiannakis, Georgios (2017). The Role of Teacher in Primary School Students' Mental Health Promotion. Global Journal of Human-Social Science: A Arts \& Humanities - Psychology, Volume 17 Issue 5 Version 1.0.

Pekrun, R. (2000). A Social-Cognitive, Control-Value Theory of Achievement Emotions. In J. Heckhausen (Ed.), Motivational psychology of human development (pp. 143-163). Oxford, England: Elsevier.

Pekrun, R., Goetz, T., Titz, W., \& Perry, R. P. (2002). Academic Emotions in Students' SelfRegulated Learning and Achievement: A Program of Qualitative and Quantitative Research. Journal of Educational Psychology, 37, 91-106.

Rosaen, C. \& Benn, R. (2006). The Experience of Transcendental Meditation in Middle School Students: A Qualitative Report. Explore, 2, 422-425.

Segal, Z. V., Williams, J. M. G., \& Teasdale, J. D. (2002). Mindfulness based Cognitive Therapy for Depression: A New Approach to Preventing Relapse. New York: Guilford.

Semple, R., Reid, E., \& Miller, L. (2005). Treating Anxiety with Mindfulness: An Open Trial of Mindfulness Training for Anxious Children. Journal of Cognitive Psychotherapy, 19(4), 379-392.

Shapiro D, Cook IA, Davydov DM, Ottaviani C, Leuchter AF, Abrams M. (2007). Yoga as a Complementary Treatment of Depression: Effects of Traits and Moods on Treatment Outcome. Evidence-Based Complementary and Alternative Medicine, 4(4), 493-502.

Siegel \& Fulton (2005). Mindfulness and Psychotherapy. New York, London: The Guilford Press. 
Siegel, D.J., (2009). Mindful Awareness, Mindsight and Neural Integration. The Humanistic Psychologist, 37, 137-158.

Simon B. Goldberg, Laura Pinger, Katherine Bonus, and Richard J. Davidson (2013). Mindfulness for Teachers: A Pilot Study to Assess Effects on Stress, Burnout And Teaching Efficacy. Mind Brain Education, 7(3).

Singh, N., Nirbhay N. Singh, Giulio E. Lancioni, Subhashni D. Singh Joy, Alan S.W. Winton, Mohamed Sabaawi, Robert G. Wahler, Judy Singh (2007). Adolescents with Conduct Disorder Can Be Mindful of Their Aggressive Behaviour. Journal of Emotional and Behavioural Disorders, 15(1), 56-63.

Sogyal, R. (1992). The Tibetan Book of Living and Dying. Sydney: Random House.

Swartz, R. A., \& McElwain, N. L. (2012). Preservice Teachers' Emotion-Related Regulation and Cognition: Associations with Teachers' Responses to Children's Emotions in Early Childhood Classrooms. Early Education and Development, 22, 202-226.

The Mental Health Act (1987). Government of India. Retrieved February 3, 2016. Mental Health Inventory (MHI) 38 Training Manual and Slides. Retrieved http://www.amhocn.org/publications/mental-health-inventory-mhi-38-trainingmanualand-slides).

World Health Organization (August 2014). Mental Health: A State Of Well-Being. Retrieved from https://www.who.int/features/factfiles/mental_health/en/

Zylowksa, L., et al. (2008). Mindfulness Meditation Training in Adolescents and Adults with ADHD: A Feasibility Study. Journal of Attention Disorders, 11(6), 737-746. 